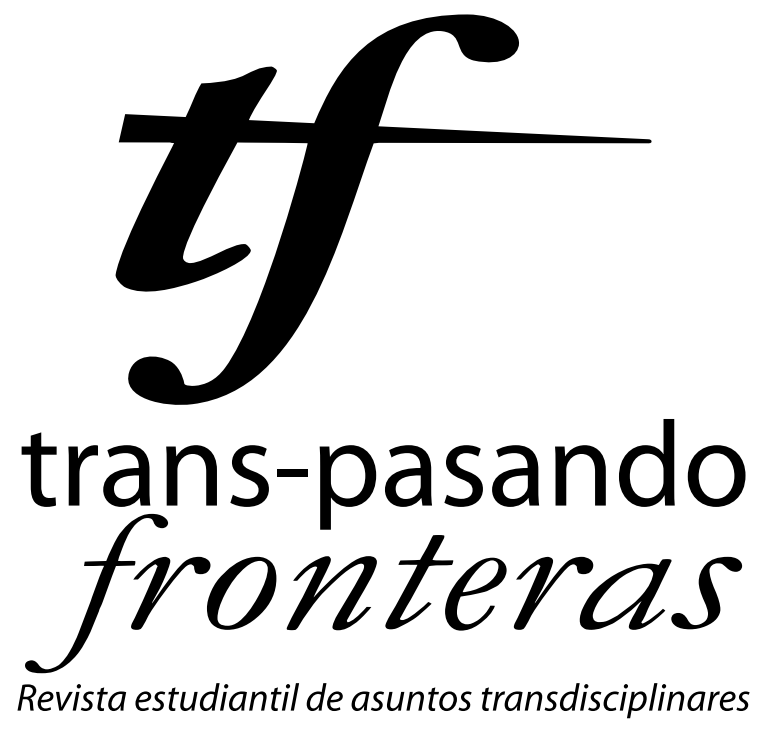

Una publicación de

Facultad de Derecho y Ciencias Sociales

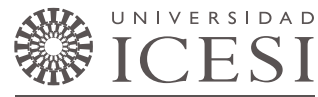




\title{
Establecimiento del PIN dentro del sistema de partidos colombiano
}

\author{
Vanessa Ortiz \\ (vai_29@hotmail.com)
}

\author{
Alejandra Quintero \\ (aleja_qa@hotmail.com)
}

Artículo de investigación científica y tecnológica recibido el 25/05/2012 y aprobado el 17/10/2012.

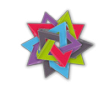

Como citar este artículo:

QUINTERO. Alejandra y ORTIZ. Vanessa (2012). "Establecimiento del PIN dentro del sistema de partidos colombiano". En: Trans-pasando Fronteras, Núm. 2, pp. 47-63. Cali, Colombia: Centro de Estudios Interdisciplinarios, Jurídicos, Sociales y Humanistas (CIES), Universidad Icesi.

\begin{abstract}
Resumen
Este trabajo se constituye como una revisión de la contienda electoral legislativa celebrada en el país en el año 2010, y de cómo ésta tuvo como principal resultado el establecimiento del Partido de Integración Nacional (PIN) dentro del Sistema de Partidos colombiano. Dicha investigación se realizó a partir de la recopilación de prensa pertinente al tema y su correspondiente análisis a la luz de las variables: financiación, constitución jurídica, aceptación popular y tiempo de establecimiento. De este modo el presente artículo intenta comprender como el PIN, logró hacerse un lugar dentro del Sistema político y cuales serían las posibles consecuencias de dicho fenómeno, específicamente, para el departamento del Valle del Cauca.
\end{abstract}

Palabras claves:

Partido de Integración Nacional (PIN), Elecciones 2010, Sistema de Partidos Colombiano, Sistema Electoral Colombiano. 


\section{Introducción}

El presente análisis pretende comprender el establecimiento del Partido de Integración Nacional (PIN) dentro del Sistema Electoral Colombiano, en las elecciones legislativas para la Cámara de Representantes de 2010, en el departamento del Valle del Cauca.

Para entender el comportamiento experimentado por el PIN durante el proceso electoral, se requiere del estudio de las variables: financiación, constitución jurídica, aceptación popular y tiempo de establecimiento. En estos términos se plantea que si bien el PIN, a pesar de tener poco tiempo de constitución, integra en sus listas a personas con antecedentes penales, además de tener una dudosa financiación durante su campaña y presentar problemas en su constitución legal, logró establecerse exitosamente como partido dentro del Sistema Electoral Colombiano superando todas las condiciones legales que la legislación electoral impone. Este sentido, esta investigación se centrará en la influencia de las redes clientelares, el manejo incorrecto del presupuesto y la compra de votos, en dicho proceso.

Se establece como objetivo general analizar los procesos del departamento del Valle del Cauca que permitieron la instauración del PIN dentro del Sistema Electoral Colombiano; y como objetivos específicos: a). Indagar sobre los mecanismos utilizados por el PIN para financiar las campañas políticas de los miembros de sus listas, en el Valle del Cauca. b). Examinar las posibles redes de poder que le permitieron al PIN hacerse un espacio dentro de la arena política del país. c). Explorar la veracidad de las acusaciones hechas contra el PIN, acerca de la compra de votos. d). Revisar los antecedentes penales de algunos de los miembros de sus listas.

Para cumplir con estos objetivos, se recurrió a técnicas tanto cualitativas como cuantitativas. Se designaron unas variables de análisis y a continuación se realizó una revisión bibliográfica y de prensa. Se agrupó la información recogida según dichas variables para luego proceder con la descripción de la coyuntura y finalmente desarrollar la hipótesis. En congruencia con lo anterior, se dividió desarrollo del artículo en tres grandes bloques. Primero, sección introductoria, se refiere a contenidos metodológicos; segundo, se remite a las concepciones teóricas con las que se desarrollará el análisis; y tercero, que incluye el cuerpo del análisis, es decir, la reconstrucción de la coyuntura y el procesamiento de la hipótesis, además de las respectivas conclusiones. 


\section{Base Teórica}

Para el desarrollo de este análisis se ha decidido utilizar las siguientes definiciones de conceptos por considerárseles fundamentales para el mismo, a pesar de la multiplicidad de significados que estos tienen. La definición de partido político resulta fundamental para ahondar en el análisis de coyuntura que estamos examinando. Por éste se entiende "cualquier grupo político que se presenta a elecciones y que puede colocar mediante elecciones a sus candidatos en cargos públicos" (Sartori; 2005: 101). Igualmente, la ley colombiana promulga, que será entendido por partidos políticos aquellas "instituciones permanentes que reflejan el pluralismo político (...) Los partidos y movimientos políticos constituidos con el lleno de todos los requisitos constitucionales y legales tendrán personería jurídica" (Ley 130, Art. 2).

En nuestro caso, el partido estudiado se autodenomina como un "partido político de ámbito Nacional fundado el 9 de Noviembre del 2009, bajo el respeto a la dignidad humana, al trabajo, la solidaridad, en donde prevalece el interés general. Un partido con carácter Social, Empresarial, Cultural, Democrático, Participativo, Pluralista, Pacifista y Ambientalista [...] defiende y contribuye al desarrollo del Estado Social de Derecho" (¿Quiénes somos?; www.partidopin.com)

Es necesario conocer cómo funciona el sistema electoral colombiano, para entender las acciones que realizó el PIN durante las elecciones a la Cámara de Representantes para el Valle del Cauca de 2010, según lo establecido por la Ley Estatutaria de Partidos Políticos (LEPP) de 2003, el Sistema Electoral Colombiano tiene una magnitud electoral de 100 escaños para el Senado con una circunscripción nacional y de 13 escaños para la Cámara de Representantes con circunscripción Valle del Cauca. La fórmula de repartición de votos a utilizar será la $D^{\prime} H o n t$ o comúnmente conocida como cifra repartidora. Igualmente, "para todos los procesos de elección popular, los Partidos y Movimientos Políticos presentarán listas y candidatos únicos, cuyo número de integrantes no podrá exceder el de curules o cargos a proveer en la respectiva elección" (Constitución Nacional, Art. 263).

Además, en Colombia existen "dos sistemas electorales según el tamaño de las circunscripciones: 1) Para aquéllas en las que deban elegirse tres o más curules, umbrales a) del $2 \%$ sobre la votación total en el caso del Senado, y b) de un $50 \%$ del cociente electoral para 
Cámara, Asambleas, Concejos, JAL, etc. y método de escrutinio de la llamada "cifra repartidora", y 2) Para aquéllas en las que deban elegirse dos curules (y en los nueve nuevos departamentos para la Cámara) el umbral se reduce al 30\% del cociente electoral (o un 15\% de la votación total) y el método de escrutinio es el del cociente electoral" (Delgado, 2002).

En el caso de las listas, específicamente para el Senado, como también es afirmado por Delgado, desde la reforma política de 2003, se añade al sistema electoral la "lista única con voto preferente opcional”, en la que el votante podrá elegir el candidato de su preferencia del partido político con el que tenga afinidad. De acuerdo al sistema de umbrales, para lograr obtener una curul dentro del Congreso colombiano, necesita, en caso tal de que quiera hacer parte del Senado, el $2 \%$ de votos válidos y el cuociente/ 2 para la Cámara de Representantes (Delgado, 2002).

Los partidos políticos en Colombia según la Constitución política del 91, en los artículos 40 y 108; deben de estar legalmente constituidos teniendo en cuenta que cualquier ciudadano colombiano tiene la autonomía de construir partidos, movimientos políticos y agrupaciones políticas, bajo ninguna limitación, además de hacer parte de estas agrupaciones políticas sin limitación alguna, difundiendo libremente sus ideas y programas, teniendo en cuenta, que de acuerdo a la definición de partido político, expresada en el Artículo 2. el cual afirma que, dichas instituciones formales creadas en búsqueda de reflejar el pluralismo político del país, pueden tener participación activa dentro del sistema si y sólo si, cumplen con todos los requisitos constitucionales y legales arrojados por la Constitución. Por lo que el Consejo Nacional Electoral (CNE), reconocerá su personería jurídica si cumple con los requisitos legales, y sostendrán su vigencia dentro del sistema de partidos, en la medida que logre una representatividad de votos no inferior al $2 \%$ en todo el territorio nacional, para el caso especifico del Senado y la Cámara de Representantes.

Mientras los partidos o movimientos políticos colombianos tengan personería jurídica reconocida, podrán inscribir a sus candidatos sin requisito alguno (LEPP, 2003:14-15). Con relación a la financiación de un partido político durante las campañas según el Artículo 13 y 14 de la Constitución, el Estado colombiano dará un aporte a la financiación de las campañas electorales de los partidos y movimientos políticos. Para el caso de los Aportes Particulares, tanto los partidos y movimientos como candidatos, podrán recibir ayuda económica de personas naturales y jurídicas. Las sumas invertidas en la campaña 
son de acuerdo a lo que el Consejo Electoral Nacional establezca (LEPP, 2003:19-20).

Este sistema se ha visto permeado por la corrupción electoral, fenómeno que se evidencia en las elecciones del Congreso de 2010, particularmente, con el partido PIN. Por eso es necesario, a pesar de que no existe una definición concreta, a lo largo de este análisis se comprenderá por corrupción electoral todos aquellos fenómenos que durante el proceso electoral, trunquen o modifiquen la elección y que, sobretodo, no se contemplen dentro de lo establecido por la ley, es decir, todo lo que se entiende como delitos electorales que, según la Misión de Observación Electoral (MOE) y la Ley 1142 de 2007 del Código Penal Colombiano, pueden ser 11: la perturbación del certamen democrático, el constreñimiento al sufragante, el fraude al sufragante, el fraude a inscripción de cédulas, el corrupción al sufragante, el voto fraudulento, favorecimiento al voto fraudulento, la mora en la entrega de documentos relacionados con una elección, la alteración de resultados electorales, el ocultamiento, la retención y posesión Ilícita de cédula, y la denegación de inscripción.

Otra característica esencial de la forma de actuar del PIN durante las elecciones es el establecimiento de una red clientelar para tener éxito dentro de las mismas, por lo que para el desarrollo de este trabajo, se entenderá redes clientelares como aquellas que surgen de la relación "patrón- Cliente" que establece el político con líderes populares y empresas privadas, en búsqueda de la acumulación de votos durante campaña electoral. Dentro de esta red se delimita una relación de poder que tiende a la horizontalidad, en donde cada uno de los dos actores tienen algo a ofrecer que beneficia al otro. Esta red se da en torno a una cadena de "favores políticos" que se derivan en resultado electorales durante la contienda electoral. A pesar de que tiene otros matices, dentro de este trabajo se va a tocar su utilidad dentro de elecciones populares.

La definición de una red clientelar varía mucho de acuerdo a las particularidades que esta tenga, además del sistema político en el que se esté presentando. Para el caso colombiano, particularmente el vallecaucano, aun no se ha realizado una conceptualización del tema. Se podría considerar un acercamiento, aunque no hecho para el caso especial del Valle de Cauca, afirmar que "los agentes operan en tres niveles; el primero, como relaciones entre dos personas, el segundo, como conexiones entre agregados de personas y patronos o burócratas, y el tercero, como 'interfaces' que vinculan comunidades enteras a la sociedad. Las características de los agentes mismos, las cualidades personales que 
los empujan a su posición, también emergen como factores importantes para entender su conducta". Con esta percepción, se puede identificar las faces que tiene el clientelismo como proceso, es decir, aquí se evidencia como este no es una mera relación de patróncliente, sino que también hay otros actores que hacen parte de este telar que los moviliza según intereses electorales, económicos y profesionales.

Cada político, establece su red según el alcance que tenga, los contactos y las influencias económicas que tenga se hacen fundamentales, no solo para establecer la red, sino también para fortalecerla y mantenerla con el tiempo. De la estabilidad de la misma depende el éxito tanto en periodo electoral como en la incidencia que tenga el actor político sobre las decisiones públicas y en ciertos casos privadas del país. Ahondar en los roles que cada actor tiene dentro y fuera de la red, permite observar cómo los intereses electorales forman todo un tejido que da paso a una interacción particular con el otro dentro del ejercicio de la política. Como lo afirma Schmitter, este "significa el fenómeno que provoca en la gente estratificación por jerarquias de gran autoridad creciente, y como tal es quizás más útil que el análisis de clase, puesto que permite analizar relaciones de autoridad en comunidades donde no cuenta, por ejemplo, la ausencia de diferenciación de riqueza".

El clientelismo se ha convertido en un fenómeno institucionalizado informalmente dentro del ejercicio de la política. Para el caso del Valle del Cauca y de Colombia en general, de acuerdo a cómo, con quién y bajo qué condiciones se establecen los vínculos clientelares depende el éxito electoral y la vigencia e influencia del político en el sistema. Además de establecer una red clientelar, la compra de votos fue otra constante durante el proceso electoral, a la cual entenderemos a la luz de la Ley 1142 de 2007 como "la promesa, pago o entrega de dinero o dádiva a una persona habilitada para votar para que sufrague por un candidato, partido político o voto en blanco ó se abstenga de hacerlo. La pena es de 3 a 5 años de cárcel y una multa de 100 a 500 salarios mínimos legales vigentes. El sufragante que acepte tendrá una condena de 1 a 2 años". Al ser el voto libre y autónomo, comprarlo resulta en el caso colombiano un delito electoral penalizable. La compra de votos esta vista como un acto deslegitimo que altera la funcionalidad integral del Sistema Electoral Colombiano. Este obliga a que el votante no elija a la persona que él considera adecuada para ocupar el cargo público, según su preferencia, sino que vote por el que el comprador de su decisión le exija. 


\section{Análisis}

Para comprender el establecimiento del PIN como partido político, a partir de las elecciones legislativas para la Cámara de representantes de 2010 en el Valle del Cauca, es de vital importancia ver cuáles fueron los procesos históricos que anteceden a la formación del mismo.

\section{De Convergencia Ciudadana al Partido de Integridad nacional (PIN)}

Previo a su establecimiento como PIN, este se conocía como Convergencia Ciudadana. Dicho partido, fue constituido legalmente el 24 de Julio de 1997, como el partido número 171, bajo la coordinación de Luis Alberto Gil Castillo, quien en la época se desempeñaba como diputado del departamento de Santander. Ese partido se constituyó como uno de los principales opositores a los partidos tradicionales colombianos, lo cual le representó una curul en el Senado de la República en las elecciones del año 2002, Más adelante, para el año 2003 el partido, fuertemente constituido, contaba con un gobernador (en el departamento de Santanter) y 21 alcaldías alrededor del país; siendo el noveno partido más votado en Colombia. Lo particular de esto, es que logró alcaldías en municipios históricamente vinculados a escándalos de corrupción y presencia paramilitar como Arauca, Puerto Wilches, etc.

Para el año 2006, el partido logró siete escaños en el Senado de la República, para los candidatos Luis Alberto Gil, Juan Carlos Martínez Sinisterra, Oscar Josué Reyes, Luis Eduardo Vives, Carlos Barriga, Gabriel Acosta y Samuel Arrieta, quienes son llamados el año siguiente a rendir declaratoria ante la Fiscalía por sus aparentes vínculos con los paramilitares. A la par, se abre una investigación sobre su presunta financiación ilegal en campaña. Conforme a esto, la opinión pública, los medios de comunicación y las ONG's empezaron a hacer señalamientos considerables a políticos de Convergencia Ciudadana, lo cual los desprestigió aún más e hizo que perdieran credibilidad, hasta el punto que el ex presidente Uribe, expulsó formalmente al partido del ala uribista.

Por otro lado, el caucano Juan Carlos Martínez, fue igualmente investigado a raíz de su presunta cercanía con Wenceslao Mosquera y Olmer Durán Ibarguen, reconocidos narcotraficantes, como lo afirman León Valencia y Oscar Sevillano. Además de considerársele heredero del caudal electoral de Carlos Herney Abadía, el cual a su vez fue investigado en el proceso 8.000. Sin embargo, Martínez es considerado uno de los más poderosos jefes políticos del Valle, pues cuenta con un caudal electoral bastante amplio, lo que en un futuro le permitiría liderar una de las facciones del PIN. 
Todas estas acusaciones hicieron que el partido perdiera credibilidad entre el electorado, por ello, sus miembros deciden darle una nueva imagen y así no perder la personería jurídica que se les había otorgado, como se afirma en el Acta 197 de las sesiones ordinarias del partido. Cambió pues su nombre a Partido Alianza Demócrata Nacional. El ADN (Alianza Demócrata Nacional), entre el 10 y el 19 de octubre y 19 de noviembre de 2009. Sin embargo, este "nuevo" partido, era integrado por tan solo una facción del antiguo convergencia ciudadana, aquel liderado por el ex senador Juan Carlos Martínez.

Sin embargo, el Consejo Nacional Electoral dictamina el 28 de enero de 2010 al haberse violado los procedimientos de constitución legal en la transición de un partido a otro, decide quitarle la personería jurídica, obligándolos a cancelar las inscripciones a la candidatura al Congreso de la República durante las elecciones de marzo de 2010. De acuerdo a los reportes dos de los Ex congresistas que hacían parte del proceso de transformación estaban detenidos en la cárcel La Picota y otros dos estaban siendo investigados por relaciones cercanas con los paramilitares.

La aparición del ADN en el Valle del Cauca fue muy particular. Su principal promotor, Juan Carlos Martínez, se encontraba en la cárcel. Además, debido a los fuertes nexos del anterior gobernador del departamento, Juan Carlos Abadía, se logró lanzar a la luz pública el nombre de este, antes de la fecha establecida por el Consejo Nacional Electoral, en lugares públicos de gran concurrencia, como lo fue en época decembrina la Plaza de Toros de la ciudad de Cali y uno de los eventos más importantes de la Feria, el Súper Concierto, entre otros. El despliegue que tuvo este partido fue criticado, no sólo por lanzar su nombre antes de la fecha prevista, sino también por mostrar cercanía con entes gubernamentales, como lo era la gobernación del Valle.

Casi que paralelamente a este proceso, la otra facción del antiguo Convergencia Ciudadana, aquel liderado por la empresaria del chance Enilce López y por Luis Alberto Gil, crearon otro nuevo partido, llamado Partido de Integración Nacional PIN. Este fue constituido desde el 9 de noviembre de 2009, como resultado de la conjugación de varias fuerzas políticas provenientes de diversos sectores sociales y empresariales de Colombia, integrado y avalado, por algunos políticos de vieja data y ex miembros de las fuerzas públicas, como lo son Carlos Herney Abadía, Juan Carlos Martínez, y el retirado General Jesús Antonio Gómez Mendez, entre otros. A través de negociaciones sostenidas entre 
Luis Alberto López y Enilce López, alias la Gata, surge la iniciativa de crear dicho partido, invitando a sus seguidores a adherirse a él. Entre las tácticas utilizadas, propuso "a los ediles que al que se pasara a Convergencia le daba 20.000 pesos por cada voto recibido en las elecciones pasadas. Esa oferta implica que los concejales recibirían entre siete y 30 millones de pesos, según sus votos" (Valencia; 2010). Después de enero de 2010, a partir de la pérdida del ADN, sus miembros entran a ser parte del PIN e inscriben sus candidaturas bajo su aval.

Por otro lado, se plantea la constitución del partido como un "salvavidas" a lo que, consideran (el PIN), la fallida democracia colombiana (Estatutos, Partido Integración Nacional). El PIN se autodenomina como un partido que integra el sector "independiente, demócrata, convergente, religioso, gremial e intelectual” en un solo conglomerado.

\section{El PIN dentro del sistema político colombiano}

El inicio del PIN es diferente al de los demás partidos existentes en Colombia. Este surge de una base sólida: el antiguo partido convergencia ciudadana. No se considera un partido tradicional, si no que por el contrario, es un partido uribista que plantea una iniciativa política diferente, válida para todos los sectores sociales; por ello su lema: "Seguridad y Compromiso Social".

Durante el período electoral, el PIN desarrolló una estrategia publicitaria particular: gran cantidad con baja calidad. Las imágenes y los eslóganes no eran muy atractivos, sin embargo casi que empapelaron las ciudades del Valle con la misma, lo cual de una u otra forma generó recordación en el electorado.

Simultáneamente, durante el mismo período de tiempo, se iniciaron contra los candidatos de las listas PIN fuertes críticas y acusaciones. Según la opinión pública eran candidatos vinculados a escándalos de corrupción, para-política, e incluso, algunos de ellos habían estado en la cárcel. "Como los ex senadores Dieb Maloofy Vicente Blel. Pero ahí no para la presunta relación con 'paras' porque los otros dos miembros también son investigados por la Corte Suprema de Justicia. Ellos son Jorge Castro Pacheco -hermano del ex jefe paramilitar, 'Tuto' Castro' y un representante del investigado Habib Merheg”'(El Espectador, 2009).

Incluso el "El vocero del Partido Liberal en el Senado, Juan Manuel Galán, denunció que, "partidos que estuvieron involucrados en la para-política y que recientemente 
cambiaron de nombre, como el PIN (PIN, antiguo Convergencia Ciudadana) ${ }^{1}$, y ADN tienen grandes cantidades de dinero para comprar dirigentes y concejales con buen caudal electoral. Esos dineros provienen del narcotráfico, en una situación muy evidente en varios municipios del departamento de Santander, como Girón, Bucaramanga y todos los del área metropolitana. Hay una especie de 'tarifa' de acuerdo con los votos que tenga cada dirigente vereda o de barrio viene la paga, y que empieza en seis millones de pesos y llegan hasta los 23 y más..." (Revista Semana, 2009).

La revisión de prensa evidencia que algunos de los candidatos, estaban envueltos en problemas legales, como es el caso de uno de los candidatos a la Cámara de Representantes por el Valle del Cauca, Mohamed Duque, fue condenado a 4 años y seis meses de prisión por la fabricación, tráfico y porte de armas de fuego de uso personal. "Según lo establecido por la Fiscalía, el 31 de enero de 2009 Duque García fue sorprendido por las autoridades, en un puesto de control, con una pistola semiautomática y un proveedor con 15 cartuchos. El ahora sentenciado presentó un permiso vencido y a nombre de otra persona" (Noticias Caracol; www.caracol.com.co).

Además de esto, los candidatos a la cámara del PIN por el Valle del Cauca están permeados de otro tipo de antecedentes, como Juan Carlos Salazar Uribe, ex diputado destituido 10 años por la Procuraduría Nacional por violar el régimen de inhabilidades. Dentro del dictamen esta organización afirma que "En su decisión, la Procuraduría Regional del Valle del Cauca señaló que el señor Salazar Uribe se inscribió y salió electo como diputado del mencionado departamento para el periodo constitucional 2008-2011, pese a que su progenitora, la señora Rosa Gladys Uribe de Salazar, se inscribió como candidata para el concejo municipal de Dagua (Valle) para ese mismo periodo, hecho que constituye una inhabilidad para los diputados" (Procuraduría Nacional, 2010). Las acusaciones y antecedentes del congresista Salazar Uribe no terminan ahí, la Revista Semana afirma que el "recién elegido representante a la Cámara por el PIN, pudo haber presionado indebidamente a empleados públicos del Valle para que votaran por él”.

Las cosas no mejoraron con la participación del PIN en las siguientes elecciones parlamentarias del 14 de marzo de 2010. El escándalo aumentó, debido a que los escru-

1 Los anteriores dirigentes están todos en la Picota y en remplazo del antiguo dueño, Luis Alberto Gil, entró a la campaña su esposa 
tinios, dieron a este nuevo partido, 3 curules para la cámara de representantes, lo que se constituye casi en 4 partes de la magnitud electoral.

Además de esto, uno de los generales implicados en la masacre de Jamundí hace parte del pool de candidatos del PIN, y la mayoría de sus integrantes como Luz Dary Roa Prado, según investigaciones de la silla vacía, hace parte del grupo de políticos colombianos denominados "Los herederos de la narco política en el Valle del Cauca", como lo afirma la silla vacía en su informe.

Puede decirse que las variables de estudio, ayudan a comprender cómo todos aquellos sujetos, procesos y estructuras descritas anteriormente como antecedentes históricos del partido y de sus funcionarios, clientelismo, compra de votos, aceptación popular, manejo del presupuesto, fortalecen o debilitan los procesos democráticos en Colombia. La constitución jurídica de partidos en Colombia, por su parte, habla claramente de cómo se compone el partido. Faltar a la norma, o tener baches en el sistema legal se traducen igualmente en el mal funcionamiento de la democracia. La aceptación popular, por otro lado, legitima el accionar del partido. Las altas votaciones evidencian que, a pesar de los baches en la financiación y la constitución jurídica, los electores pudieron haber sido manipulados para votar dicho partido. Por último, el tiempo de establecimiento, que en situaciones normales, jugaría en contra de los nuevos partidos, en este caso no fue impedimento para un éxito rotundo en materia electoral.

De acuerdo a lo encontrado, a las publicaciones que se han hecho sobre la transición del PIN como partido, y la influencia del mismo en el sistema político del país, más los resultados electorales que tuvo en el Valle del Cauca durante la contienda para lograr representatividad en la Cámara de Representantes, se puede afirmar que el PIN, no se puede clasificar como un partido nuevo dentro del Sistema de Partidos Colombiano. Este partido ha sido producto de una mutación constante del que inicialmente fue Convergencia Ciudadana, movimiento político que entró en vigencia desde 1997.

A pesar de querer limpiar su imagen, sacando del partido políticos con antecedentes judiciales y transformando la apariencia del partido, el PIN no logró dejar atrás su oscuro pasado. Aún, los miembros de sus listas tenían antecedentes penales altamente criticados por la opinión pública (previamente establecidos), además de esto la financiación de sus campañas no cumplían con los estatutos del Consejo Nacional Electoral, fue evidente 
para la luz pública los altos costos que asumió tanto el partido, como sus integrantes y patrocinadores para la financiación de las campañas políticas. Los dineros de dudosa procedencia usados para la mantención del partido, más las fuertes acusaciones de compra de votos en varias regiones del Valle del Cauca, además de los altos niveles de votación que tuvo el PIN en varios municipios del departamento y los nexos con entes gubernamentales que sirvieron para el establecimiento de una red clientelar en la región, red de la cual no se tiene datos específicos, pero que se hace evidente al ver las dinámicas de partido y sus candidatos dentro de la contienda electoral.

\section{El PIN y las elecciones parlamentarias de 2010 en el Valle del Cauca}

A pesas de las fuertes críticas y acusaciones formales e informales que ocasionaron un estallido público afectando la imagen y credibilidad del partido, no se ha logrado demostrar con pruebas contundentes que dicho este lograse ocupar el espacio político que tiene ahora por medio de medios ilícitos, solo se puede evidenciar la fuerza de su maquinaria política y las fuertes alianzas clientelares que ha ido desarrollando con el paso del tiempo. Cada una de los calificativos que se le ha dado a este partido hace parte de una serie de secretos a voces que resultan ser insuficientes a la hora de vetarlo dentro de la arena política colombiana. De todas maneras, sus escándalos y modus operandi dieron pie para que medios de comunicación, como la revista Semana, calificara a los congresistas del Valle del Cauca de "ilegítimos", como lo afirma la Revista Semana en una de sus ediciones (Revista Semana, 2010).

Los votos del Valle del Cauca tuvieron que pasar otras instancias para comprobar que el conteo de estos fue un proceso transparente, y aun así, después de arrojar los resultados electorales se sigue dudando de la veracidad de los mismos.

Uno se los mecanismos que permite ver lo niveles de aceptación que tiene cada partido político, dentro de un sistema democrático es el voto. El PIN logró obtener una suma considerable de votos en el Valle del Cauca, llegando al punto de contar con la mayoría de estos en muchos de los municipios de la región. Teóricamente la aceptación de este es más que evidente, al logran tan buenos resultados electorales, pero los mecanismos por los cuales obtuvo este resultado, permiten cuestionan quién está siendo aceptado aquí, el partido o el dinero con el cual se compraron los votos para obtener esos resultados. 
El PIN obtuvo la segunda mayor votación por lista y obtuvo 3 curules, mientras que la mayor votación fue para el partido de la U, quien obtuvo 4 curules. Esto evidencia sin duda que la aceptación popular fue amplia, sin embargo, su vinculación a escándalos de corrupción y parapolítica, además del poco tiempo de trabajo del partido, pondrían en cuestionamiento dicha aceptación. De igual modo, como se evidencia en las notas periodísticas, el PIN tuvo una alta tendencia a la compra de votos, sobretodo en la zona sur del departamento, especialmente en Jamundí, como lo afirma la MOE.

Lo anterior supone que la democracia en Colombia, en lo que respecta al Valle del Cauca, no está funcionando como idealmente se plantea. Si se entiende que la democracia tiene como ejes principales la legitimidad a través de la soberanía de los ciudadanos, puede decirse la legitimidad se dá por la aceptación del electorado ${ }^{2}$, y la legalidad, en términos estrictos no podría cuestionarse, pues si bien en el pasado los miembros del partido estuvieron involucrados en problemas legales, en la coyuntura del momento no hay nada que pueda reprochárseles en este respecto.

Es de vital importancia pues, comprender cómo dicho fenómeno afecta directamente la gobernabilidad en el país. Teniendo en cuenta que las dimensiones de la misma son la eficacia, legitimidad y estabilidad, se puede afirmar que: La estabilidad se ve reflejada en mínima medida (es necesario afirmar que se parte del supuesto de corrupción en el proceso electoral), pues el sistema fue permeado por algunos delitos electorales, lo que refleja su mal funcionamiento. Se pone en duda la capacidad de reproducción del régimen en sí mismo, pues a pesar de todos los esfuerzos por evitar este tipo de situaciones (como las reformas políticas), no ha logrado hacerlo. Por otro lado, partiendo de la premisa de que el votante es racional, podría decirse que la elección del PIN para la cámara de representantes por el Valle del Cauca fue totalmente eficaz: se supone que los candidatos responderían a las demandas de los electores, al menor costo posible

Al ser la estabilidad del sistema político fundamental para que este perdure a pesar de las externalidades, es claro aquí, que el PIN logró detonar una bomba de previo aviso que atentó contra la democracia colombiana. Se han hecho afirmaciones de que el Sistema político de Colombia ha logrado perdurar con el tiempo a pesar de este ser un país inundado

2 Legitimidad que de todos modos, está en duda por los escándalos de compra de votos, por lo que por ende, la soberanía de los ciudadanos también estaría en duda. 
por la violencia y la corrupción, pero las evidencias muestran lo contrario. El principio de la libertad de elección dentro de un Sistema democrático ha sido fácil de violar al ser este un país que padece de una débil condición social. Las fuerzas políticas, como el PIN, han logrado convertir las desventajas sociales en estrategias ganadoras para los candidatos que participan en contienda electoral. La compra de votos se ha hecho cada vez más fácil en la medida en que la gente tiene cada vez menos para comer, y el establecimiento de las redes clientelares se convirtió en una forma fácil de conseguir empleo a cambio de votos.

Estas entre otras condiciones sociales han facilitado cada uno de los delitos electorales y procedimientos atípicos, pero no penales, que el PIN, junto con otros partidos colombianos, han utilizado como estrategia de campaña para tener éxito en las elecciones, mostrando así, que muchos de los ciudadanos de Colombia cambiaron su libertad electoral por un plato de comida, una monedas o un empleo.

Cada uno de los delitos y comportamientos inapropiados antes, dentro y después de la contienda electoral evidencian como la "estabilidad" de la que muchos se sienten orgullosos, se va dejando opacar por el entorno. Todo esto logra afectar de tal forma en la población, que los candidatos que logran ser "representantes del pueblo" padecen de bajos niveles de gobernabilidad por la incredibilidad de su trabajo para los colombianos. A pesar de no haber en muchos casos pruebas contundentes con las que se pueda afirmar que los políticos, del PIN para este caso específico, son corruptos, las acusaciones hacen que los indicen de gobernabilidad bajen al hacerse invisibles las obras publicas que cada uno de estos prometió cumplir, más la fuerte evidencia de que tanto el sistema como las instituciones son cada vez más débiles.

Finalmente el sistema de pesos y contrapesos en el Congreso, se ve directamente influido, pues el PIN, al considerarse uribista, entra (con sus 3 curules), a formar parte de la coalición uribista, dejando menos espacio de participación para otras corrientes políticas, en otras palabras, genera polarización.

\section{Conclusiones}

A manera de conclusión, puede decirse que la presente coyuntura es solo un reflejo de la realidad. Se hace visible como los políticos colombianos que tienen un pasado "oscuro", se ven en la necesidad de crear partidos políticos nuevos o transformarlos para ser triunfadores dentro de la contienda electoral, particularmente las elecciones a Congreso 
de 2010. Es evidente, que la mutación de un partido político se convierte en una carta de juego indispensable para polarizar los actos delictivos que cada uno de sus integrantes ha cometido. No importan los delitos cometidos por sus integrantes, el jolgorio que causa la transformación de un partido los oculta, dando la impresión de que, como en el mercado, cada producto "nuevo" es mejor.

El sistema político, en cierta medida, se ha convertido en un sistema permisivo, pues este tipo de irregularidades se han constituido en eventos regulares, lo cual es totalmente contraproducente en una democracia. Por otro lado, se da una especie de moldeamiento de la democracia, pues institucionaliza una serie de prácticas como el clientelismo, las cuales, en ningún caso son positivas para el sistema, pero por repetición, empiezan a ser aceptadas dentro del mismo.

El PIN es un reflejo de como al pasar los años, el sistema político colombiano se ha deteriorado, permitiendo que las externalidades permeen y corrompan su funcionamiento. Tales prácticas han llegado al punto de ser aceptadas y obligatorias para tener éxito en cualquier tipo de proyecto político en el país. De todos modos, no solo el PIN, sino también otros partidos políticos del país incumplen las normas establecidos para lograr sus objetivos, esto demuestra la flexibilidad y debilidad de la democracia colombiana.

\section{Bibliografía}

CONGRESO DE LA REPÚBLICA DE COLOMBIA - LEPP (2003). Ley Estatutaria de partidos políticos, marzo de 2003. Bogotá.

DELGADO, Óscar (2003). "La Reforma Politica Constitucional en Colombia”. En: Observatorio Electoral. Consulta realizada desde: http://www. observatorioelectoral.org/biblioteca/?bookID $=27$

DIARIO EL PAÍS (2010a). “Así quedo la Cámara de Representantes por el Valle del Cauca". En: Diario El País, 19 de julio de 2010. Cali. Consulta realizada desde: http://www. elpais.com.co/elpais/valle/noticias/asi-quedo-camara-representantes-por-valle-del-cauca (2010b). “Se acaba el "reinado" del PIN en el Valle del Cauca?”. En: Diario El País, 20 de marzo de 2010. Cali. Consulta realizada desde: http://www.elpais. com.co/elpais/valle/acaba-reinado-del-pin-en-valle

- (2010c). "Procuraduría confirma destitución de secretario de Educación 
del Valle”. En: Diario El Pais, 26 de agosto de 2010. Cali. Consulta realizada desde: http://www.elpais.com.co/elpais/valle/noticias/procuraduria-confirma-destitucion-secretario-educacion-del-valle (2010d). "Procuraduría destituyó a ex diputado del Valle del Cauca". En: Diario El País, 10 de marzo de 2010. Bogotá. Consulta realizada desde: http://www.elpais. com.co/elpais/valle/noticias/procuraduria-destituyo-ex-diputado-del-valle-del-cauca

EL ESPECTADOR (2010). "Suspendida personería jurídica del Partido ADN". En: El Espectador, Sección Política; 28 de enero de 2010. Bogotá. Consulta realizada desde: http:// www.elespectador.com/noticias/politica/articulo184521-suspendida-personeria-juridicadel-partido-adn

EL UNIVERSAL (2010). "Es urgente reformar el Sistema Electoral”. En: El Mundo; abril 15 de 2010. Medellín. Consulta realizada desde: http://www.eluniversal.com.co/ cartagena/politica/es-urgente-reformar-el-sistema-electoral

LA SILLA VACÍA (2010). "Los herederos de la narco política en el Valle”. En: $L a$ Silla Vacía, 12 de marzo de 2010. Bogotá Consulta realizada desde: http://www.lasillavacia.com/historia/8046

PARTIDO DE INTEGRACIÓN NACIONAL - PIN (s.f.). ¿Quiénes somos?. Consulta realizada desde: http://www.partidopin.org/page/propuesta-politica

PARTIDO DE INTEGRACIÓN NACIONAL - PIN (s.f.). Estatutos PIN. Consulta realizada desde: http://api.ning.com/files/6VO5b-91Zo0*rkEF6hFX2DrAWm9k1quyYglEt*1 f3DkBAzFfCWtNgg9Eoqq3waCkPBn8k5Ifw8Q6JerbO4CDaiV2I2QtT9wI/estatutos.pdf

PROCURADURIA GENERAL DE LA NACIÓN (2010). Destituido ex diputado del Valle del Cauca. 7 de julio de 2010. Bogotá. Consulta realizada desde: http://www. procuraduria.gov.co/html/noticias_2010/noticias_454.htm

REGISTRADURIA NACIONAL DEL ESTADO CIVIL (2010), Resultados elecciones legislativas 2010, para el Valle del Cauca. Consulta realizada desde: http://www. registraduria.gov.co/index.htm

REVISTA SEMANA (2010a). "Candidato del PIN, culpable de porte ilegal de armas". En: Revista Semana, 17 Febrero 2010. Bogotá. Consulta realizada desde: http://www.semana.com/actividad-politica/candidato-del-pin-culpable -porte-ilegal-armas/135091-3.aspx 
(2010b). "El fenómeno del PIN". En: Revista Semana, 6 Febrero 2010- Bogotá. Consulta realizada desde: http://www.semana.com/nación/fenomeno-delpin/134631-3.aspx

(2010c). "En el Valle, otro congresista del PIN cuestionado" En: Revista Semana, 8 de Agosto de 2010. Consulta realizada desde: http://www.semana.com/ nacion/valle-otro-congresista-del-pin-cuestionado/142822-3.aspx

(2010d). "La paliza en el Valle". En: Revista Semana; 19 de marzo de 2010. Bogotá. Consulta realizada desde: http://www.semana.com/noticias-elecciones-2010/paliza-valle/136547.aspx

(2010e). "La pelea por el Valle". En: Revista Semana; Sección Política; 5 de marzo de 2011. Consulta realizada desde: http://www.semana.com/noticias-nacion/ pelea-valle/152869.aspx

SARTORI Giovanni (2005). Partidos y sistemas de partidos: Marco para un análisis. Editorial Alianza, Madrid.

SCHMITTER, Phillip (1999). "Critical Reflexions on the "Functions" of political parties and their Perfomance in Neo-Democracies". En Demokratie in Ost und West, Wolfgang Merkel and Andreas Busch (Eds.), pp. 475-495. Frankfurt/M.: Suhrkamp Verlag GmbH und Co. KG.

SECRETARÍA DEL SENADO - LEY 130 (1994). "Ley 130 del 23 de marzo de 1994". En: Diario Oficial, No. 41280. Colombia. Consulta realizada desde: http://www. secretariasenado.gov.co/senado/basedoc/ley/1994/ley_0130_1994.html

TERRA NOTICIAS (2010). "PIN le quitó aval a uno de sus candidatos en el Valle". En: Terra Noticias, 3 de marzo de 2010. Consulta realizada desde: http://www.terra.com. co/elecciones_2010/votebien/html/vbn564-pin-lequito-aval-a-uno-de-sus-candidatosen-el-valle.htm

VALENCIA, León y Oscar Sevillano (2010). "De Convergencia al PIN". En: Ágora, 21 Mayo del 2010. Congreso Visible. Bogotá: Universidad de los Andes.

W-RADIO (2010). "Mohamed Duque García, candidato a la Cámara, es condenado a cuatro años de prisión”. En: W-Radio, 2 de marzo de 2010. Consulta realizada desde: http://www.wradio.com.co/nota.aspx?id=961541 